\title{
Is Diabetes Related to Cystic Fibrosis?
}

\section{Ritika Gupta*}

Department of Biotechnology, S.D. College of Engineering and Technology, Muzaffarnagar, Uttar Pradesh, India

Cystic fibrosis is a life threatening disease resulted by a genetic mutation of the cystic fibrosis conductance regulator (CFTR) gene. CFTR gene encodes for a chloride channel, essential for the normal flow of salt and water movements across the cell membranes. There is an improper regulation which results in thickened secretions in lung, liver, reproductive organs and pancreas. Most men with cystic fibrosis (CF) are sterile due to failure of the seminal vesicle, vas deferens, body and tail of the epididymis to develop and ejaculatory duct. Particularly salty-tasting skin, persistent coughing, shortness of breath, frequent chest and lung infections and poor growth or weight gain are some of the symptoms of cystic fibrosis within the first year of a baby's life [1]. Diabetes mellitus, episodic and chronic distal intestinal obstruction syndrome, osteoporosis, chronic liver disease, oesophageal reflux and oesophagitis, nasal polyposis, portal hypertension, allergic bronchopulmonary aspergillosis (ABPA), gallstones, respiratory and cardiac failure, pneumothorax, haemoptysis and inflammatory arthritis are some of the major complications in CF patients. A most common complication in cystic fibrosis (CF) patients is diabetes which is a unique type of diabetes also known as cystic fibrosis-related diabetes (CFRD). It has major impact on nutrition, pulmonary function and survival. In CFRD, sticky and thick mucus damages the pancreas, thus leading to insufficient insulin production which is a common symptom of type 1 diabetes. It shares the features of both type 1 and type 2 diabetes mellitus. There are two main causes for CFRD- Insulin resistance and high levels of cortisol. CFRD symptoms include increased thirst, increased need to urinate, excessive tiredness, unexplained weight loss and unexplained decline in lung function. Insulin sufficiency is caused by reduced $\beta$-cell mass due to damage in the pancreas. Abnormal chloride channel function damages the exocrine pancreas which results in destruction of islet architecture and leads to the loss of pancreatic polypeptide cells. Research is going on to demonstrate a genetic association between type 2 diabetes and CFRD. Variation in transcription factor 7-like 2 (TCF7L2) which is a type 2 diabetes susceptibility gene and a genetic polymorphism in calpain-10 are associated with CFRD. There is a biomarker of exocrine pancreatic activity known as circulating immunoreactive trypsinogen (IRT) which is found in most CF newborns. IRT declines rapidly in the first years of life in infants with severe CFTR genotypes thus reflecting progressive pancreatic damage. Therefore, the levels of IRT play an important role in predicting CFRD because by maintaining ductal secretion flow in the exocrine pancreas could help in delaying the onset of CFRD. All patients suffering from CFRD require high calorie, salt and fat diet. They usually require $120-150 \%$ of normal caloric intake, $45-50 \%$ of total energy in the form of total carbohydrate and fat. Insulin therapy tends to be the modest treatment for those patients who are in their baseline state of health because of the decreased levels of glucagon and persistence of endogenous insulin secretion [2-5].

\section{Reference}

1. Peraldo M, Fasulo A, Chiappini E, Milio C, Marianelli L (1998) Evaluation of glucose tolerance and insulin secretion in cystic fibrosis patients. Horm Res 49: 65-71.

2. Marino CR, Matovcik LM, Gorelick FS, Cohn JA (1991) Localisation of cystic fibrosis transmembrane conductance regulator in pancreas. J Clin Invest 88: 712-716.

3. Lanng S, Thorsteinsson B, Erichsen G, Nerup J, Koch C (1991) Glucose tolerance in cystic fibrosis. Arch Dis Child 66: 612-616.

4. Lanng S, Hansen A, Thorsteinsson B, Nerup J, Koch C (1995) Glucose tolerance in patients with cystic fibrosis: five year prospective study. BMJ 311: 655-659.

5. Hardin D, LeBlanc A, Lukenbough S, Seilheimer DK (1997) Insulin resistance is associated with decreased clinical status in cystic fibrosis. J Pediatr 130 948-956.
*Corresponding author: Ritika Gupta, Assistant Professor, Department of Biotechnology, S.D. College of Engineering and Technolog, Muzaffarnagar, Uttar Pradesh, India, Tel: 7060134245; E-mail: guptaritika.27@rediffmail.com

Received November 14, 2017; Accepted November 16, 2017; Published November 20,2017

Citation: Gupta R (2017) Is Diabetes Related to Cystic Fibrosis? Lung Dis Treat 3 e109. doi:10.4172/2472-1018.1000e109

Copyright: @ 2017 Gupta R. This is an open-access article distributed under the terms of the Creative Commons Attribution License, which permits unrestricted use, distribution, and reproduction in any medium, provided the original author and source are credited. 